Volume 9 | Issue 4

০o

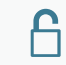

OPEN
ACCESS

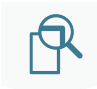

PEER REVIEWED

\title{
Platform power in the video advertising ecosystem
}

Sally Broughton Micova University of East Anglia S.Broughton-Micova@uea.ac.uk

Sabine Jacques University of East Anglia Sabine.Jacques@uea.ac.uk

DOI: https://doi.org/10.14763/2020.4.1506

Published: 13 October 2020

Received: 14 January 2020 Accepted: 29 March 2020

Funding: Centre on Regulation in Europe (CERRE, www.cerre.eu). The study and this article reflect the views of the authors only; it may not reflect the view of CERRE or its members.

Competing Interests: The author has declared that no competing interests exist that have influenced the text.

Licence: This is an open-access article distributed under the terms of the Creative Commons Attribution 3.0 License (Germany) which permits unrestricted use, distribution, and reproduction in any medium, provided the original work is properly cited. https://creativecommons.org/licenses/by/3.0/de/deed.en Copyright remains with the author(s).

Citation: Broughton Micova, S. \& Jacques, S. (2020). Platform power in the video advertising ecosystem. Internet Policy Review, 9(4). DOI: 10.14763/2020.4.1506

Keywords: Online platforms, Platforms, Platform ecosystems, Media regulation, Competition policy, Advertising

\footnotetext{
Abstract: Platform power is a societal concern on many levels. Thus, we argue that addressing it with the common market competition approach is limited. The research we present aims to develop and test an alternative approach to conceptualising and assessing platform power. We propose a framework that operationalises the concept of the integrated platform ecosystem by bounding it with theories of harm to citizen wellbeing. Applying it, instead of defining a market, we use a specific, novel theory of harm to define the audiovisual advertising ecosystem. Our investigation into the dynamics of this ecosystem and conditions shaping them incorporated elite interviews with representatives of firms involved, document analysis and an examination of legal frameworks in a sample of four European jurisdictions. The evidence we present points to an inherent bias in the opacity of trading and to systemic advantage in relationship building, as well as potential power imbalances at 'nodes' where data is used for targeting, planning, and metrics. We discuss the policy implications of these findings and suggest specific questions for regulators to be asking.
} 


\section{Introduction}

Platform power is a central concern in the internet age. As a result we have seen some high profile anti-trust investigations in Europe and the US. ${ }^{1}$ There have been many calls to address the dominant position of large platforms by using competition policy more vehemently and creatively than in the past (e.g., Crémer et al., 2019; Furman et al., 2019; Warren, 2019; Wu, 2018), and competition tools would seem the obvious choice for concerns about dominance of commercial actors. However, there is increasing evidence that the dominance of certain global platforms has much wider economic, societal and political implications than those usually addressed by interventions to promote competition (Moore \& Tambini, 2018).

We have seen an exciting turn in both scholarship and policy discussions, as debates have opened up about new ex-anti competition interventions. These include mandating data sharing or data openness and encouraging data portability (e.g. Furman et al., 2019; Stigler Center, 2019). Coyle (2018b) has suggested expanding the definition of consumer welfare within competition regulation to include consideration of innovation in adjacent markets and related effects on societal welfare from the loss of potential innovation. Intervention has been proposed to address monopsony-related impacts on labour markets where platform companies are major employers leaving workers few alternatives (Caves \& Singer, 2018). There is also evidence that regulators are increasingly thinking about privacy protections and service quality (Just, 2018). Traditional ways of assessing market power through market share, or ability to affect prices, seem inadequate in the face of these wider welfare concerns. If not defined by a market, how then can we identify problematic platform power and thereby appropriate regulatory intervention? In this article we aim to answer this both conceptual and practical question by developing and testing an alternative approach to conceptualising and assessing platform power.

Van Dijck, Nieborg and Poell (2019) advance two important conceptual steps. They argue for replacing the consumer welfare concept with one of citizen wellbeing that covers wider societal influence as well as the impact on individuals in the variety of roles they play. The authors then propose looking at integrated platform ecosystems to examine "how platforms are behaving in relation to each other,

1. The European Commission's Directorate General for Competition has fined both Facebook and Google following recent investigations (see European Commission 2017a, 2017b \& 2019) and in autumn 2019 US State Attorney Generals formally launched antitrust investigations into Facebook and Google's parent company Alphabet (see Paxton, 2019; James, 2019), followed shortly after by the US Department of Justice. 
across markets, and across societal sectors" (van Dijck et al., 2019, p. 8). Given the ubiquity and interconnectedness of platforms, this may seem like it would open a pandora's box that could not possibly be assessed by any regulator. Yet, van Dijck and colleagues call for investigation into specific case studies to reveal how power operates. We argue that such a specific case study can be delineated by defining a clear theory of harm to establish scope similarly to the way market definition enables the assessment of market power. We demonstrate here a new framework for assessing platform power that defines a specific integrated platform ecosystem case using a theory of harm to citizen wellbeing and share the findings of our study of the dynamics within that case.

The specific case from which we present results is that of the integrated platform ecosystem for video advertising. The case is delineated by a theory of harm to society and citizens from the loss of mass media, much of which is dependent or partially dependent on advertising. It focuses on video advertising, which accounts for over a third of all online display advertising in Europe (IAB Europe, 2019). The trade in video advertising brings platforms directly into competition with the audiovisual media services upon which societies depend for the production of news and culturally relevant content. The findings presented here are based on an investigation into the dynamics of relationships and decision-making in this ecosystem through elite interviews, a review of reports and other publications from platform owning companies, trade associations, public bodies, and scholars, and an examination of the legal frameworks in four jurisdictions: Belgium, France, Italy and the UK.

The first contribution of this article is to establish a new theory of harm for use in the policy debates around platforms that merges competition concerns with those associated with media pluralism and the role of media in society. The second is to introduce a new framework for assessing platform power that draws out the relationships, decision-making and dynamics within an integrated platform ecosystem revealing specific sources and locations, or nodes, of power. The kinds of power we identify are not market power, but instead are infrastructural and strategic, and provide a potential source of dominance. Thirdly, we consider the policy implications of the findings generated by the application of our framework, and outline specific information they indicate should be made transparent or made available to regulators responsible for dealing with problematic abuse of dominance in this case.

The next section traces the evolution of the conceptualisation of consumer welfare to include wider wellbeing concerns. Section three presents a theory of harm 
linked to mass media's role in citizen wellbeing. After a brief account of the methodology in section four, section five presents the integrated platform ecosystem for video advertising and findings from the examination of the relationship dynamics within it. Section six identifies where power is accumulated in the function of data in three nodes within the ecosystem. In the final section, we suggest how the findings can be used to inform policy making and argue that the examination of integrated platform ecosystems bounded by other theories of harm is necessary to ensure holistic approaches to potential platform dominance.

\section{From welfare in markets to wellbeing in ecosystems}

The expansion of online platforms has inspired scholars to re-examine some of the core concepts for assessing competition and dominance, yet operationalisable conceptualisations and frameworks that can accommodate the range of concerns are still lacking. Online platforms pose challenges for traditional competition policy because it is hard to define the markets in which they operate and what constitutes market power. Competition economists describe platforms in general using a two-sided model where there are indirect network effects of one side on the other, with zero or low costs for one side (Lerner, 2014; Rochet \& Tirole, 2006; Rochet \& Tirole, 2003). Evans and Schmalensee (Evans, 2003; Evans \& Schmalensee, 2013) argue that many platforms, including those that deal in advertising such as Google and Facebook, should be thought of as multi-sided because they are trading with a number of different groups, namely users, advertisers, content providers, app developers, and even third party data brokers. They and others (Coyle, 2018a, 2018b; Wismer \& Rasek, 2017) contend that because the welfare of these different "customers" on the different sides are intricately intertwined and subject to feedback effects, the standard competition tools for assessing market definition and market power are limited.

It is precisely these types of intertwined welfare benefits that have enabled the commercial media to fulfil a public interest role. Media supplies content to audiences for free or at low cost subsidised by the sale of their attention to advertisers. Their intertwined welfare relationships are characterised by the number of viewers and prices for advertisers and the nuisance factor of advertising for viewers (Anderson \& Jullien, 2015). This is not new. On one side, the determination of price for advertisers is a complex process involving choice of media, audience numbers, and discretionary factors such as volume discounts, rebates based on duration of commitment, and agency commissions. On the other side are a range of public interest and individual rights concerns related to citizens' use of media that cannot 
be measured by price or substitution. The notion that individuals are both citizens and consumers has been central to media regulation for some time (Lunt \& Livingstone, 2011), which is why media company mergers in Europe have been subject to special conditions related to media pluralism for decades. Media regulation is characterised by ex-anti interventions, obligations on the state, self- and co-regulatory mechanisms, and qualitative assessments of plurality and diversity.

The need to address online platforms has inspired new thinking about consumer welfare that moves in the direction of considering fundamental rights and consumers as part of a society. A wider discussion is taking place about platform dominance. Questions are commonly raised about the power that platforms have over citizens, such as, for example, in establishing new speech norms (Wagner, 2018), setting agendas (Schlosberg, 2018), political debate and democratic processes (Moore, 2018). In these we can see a concern for dominance through the dissemination of symbolic forms (Thompson, 2013) and the power to affect desires and decision-making (Lukes, 2005). These are both forms of power associated with media and the policy objective of media pluralism. The special treatment of media pluralism under competition policy acknowledges the need for citizens to be protected from undue concentrations of these forms of power, but the recognition of this has not yet inspired a reconceptualisation of power in other areas.

We point to two new directions with potential for accommodating concern for individuals as citizen within society. Firstly, competition scholars have been revising ideas about market power and consumer choice. Bamberger and Lobel (2018) point out that due to the nature of platforms, market power can restrict consumer choice in relation to their personal privacy. Competition authorities have also been expanding their considerations to non-price factors including user privacy and quality (Just, 2018). For content delivery platforms non-price factors can involve subjective characteristics such as the level and nature of child protection measures or the rigour of their moderation of user generated content for hate speech or incitement. Another concern is how the behaviour of certain platforms affects innovation in technology and services and whether it may stifle it to the detriment of society. Coyle (2018b, p. 17) points out that there can be consequences even in adjacent markets where potential innovators face issues affecting their choices and their incentives to invest and innovate, and argues that regulators "should abandon conventional market definition in favour of a wider view of the ecosystem of markets centred around a platform". The assumption here is that consumers might be negatively affected in a variety of ways by loss of investment or innovation.

The second direction addresses the problem that defining power in terms of mar- 
ket share or economic strength in relation to competitors ${ }^{2}$ does not account for power in relation to complementors or connected to the intermediary function of platforms. Strategic management and information systems scholarship have long regarded platforms as operating within ecosystems and exercising power or control over those participating in them. According to Jacobides, Cennamo and Gawer (2018, p. 2264), an ecosystem is "a set of actors with varying degrees of multilateral, non-generic complementarities that are not fully hierarchically controlled". They argue key questions should be asked as to the extent to which an online platform company wields power within an ecosystem over decision-making, such as on price or supply, and the extent to which investments made by complementors, such as app creators or product sellers on a marketplace platforms, are fungible (see also Boudreau \& Hagiu, 2009).

Online platform owners orchestrate asymmetric relationships with both consumer users and complementors within their ecosystems (Tiwana, 2014). They use a variety of mechanisms to govern their ecosystems such as controlling access to boundary resources including data, control of processes, setting levels of openness and the technical design (Schreieck et al., 2016). Seeming to echo Castells' (2011, 2013) earlier accounts of network power, Kenney and colleagues (2019) argue, "the power of platforms lies in how they can orchestrate the activities of participants, and largely determine the operation of the far more numerous complementors in the ecosystem". They identify two aspects of this power: the artifactual derived from the software and algorithms, and the contractual from their ability to set the terms and conditions for all users. This literature has done much to identify ways platform owners can exercise power over their transactional relationships with other businesses, and there has been a recent recognition that consideration of competitive dynamics requires a "shift in empirical focus from within-ecosystem to across-ecosystem dynamics" (Jacobides et al., 2018, p. 2268).

There has therefore been both the expansion of the concept of consumer welfare and a recognition that platform power can amount to dominance not only in relation to direct competitors, but also in how they interact across ecosystems. The challenge remains operationalising these in a framework that can be used in the manner that market power and consumer welfare have been. Schweitzer, Kerber and colleagues (Kerber, 2019; Schweitzer et al., 2018) propose the concept of intermediation power and argue it should be recognised as a form of market power.

2. Under European Union competition law for example dominance is defined as a position of "economic strength" that afford "the power to behave to an appreciable extent independently of its competitors, its customers and ultimately of its consumers" (United Brands Company and United Brands Continentaal BV v Commission of the European Communities., 1978). 
Using this concept, they maintain, dominance could be assessed in relation to the importance of the platform to business users for reaching certain user or customer groups and on information asymmetries. More radically, Lynsky (2017) has argued for replacing the assessment of market power with a focus on the gatekeeper function inherent in the role of platforms as intermediaries. Drawing on the earlier work by Barzilai-Nahon on network gatekeeping and Laidlaw's adaptation into internet information gatekeepers, Lynksy maintains that the concept of gatekeeper will give a much better account of online power, and that it is as much about mediating access to individuals as it is about access to information. The focus on gatekeeping has potential for marrying societal interest in having a diversity of providers with individual citizens' need for choice in order to effectively exercise their fundamental rights. However, designing regulatory intervention also requires practical ways of identifying where intermediation or gatekeeping are taking place and assessing whether they are problematic in specific instances.

Making their case for using the concept of citizen wellbeing instead of consumer welfare, van Dijck et al. (2019) echo arguments made about media regulation decades ago (see Livingstone \& Lunt, 2007). They argue that using the term citizen acknowledges democratic and civic duties and allows for consideration of the individual as part of a collective or public. Using wellbeing instead of welfare, they contend, incorporates long-term consequences and the variety of simultaneous roles citizens may play in society that one cannot "bracket off" from each other (van Dijck et al., 2019, p. 6). Their concept of an integrated platform ecosystem captures how platforms interact with each other and across multiple markets and societal sectors, offering a new way to "see how some platforms accrue unfair advantage" (2019, p. 8). Scholarship has arrived at new concepts for considering the positions of platforms, but given the pervasiveness of platforms and the breadth of wellbeing concerns involved, an additional step is still needed for these concepts to be useful in identifying sources of power or situations of dominance. This requires frameworks that can be applied to specific cases for empirical study or regulatory assessment. We therefore put forth such a framework using these two concepts.

\section{A theory of harm to citizen wellbeing}

We propose a new theory of harm to citizen wellbeing, which we use to define a specific integrated platform ecosystem case. Theories of harm that describe the anti-competitive behaviour (e.g., abuse of dominance, collusion, foreclosure) and necessitate the demonstration of harm to consumers have been the basis for com- 
petition enforcement in Europe for some time (Zenger \& Walker, 2012). In line with the expanding ideas about consumer welfare described above, there have been recent advances in these theories. These nevertheless are limited by continued focus on the connection between the conditions for competitors and prices or consumer choice. Even the novel theory of harm rooted in consumer rights to privacy (Abate, 2018) and the emerging theory of harm to innovation (Petit, 2017) appear concerned about the behaviour of competitors and choice for individual consumers. These theories are not used to determine which firms might be included in a competition investigation. Market definition, which in the EU context relies on substitutability and geographic reach (European Commission, 1997), is still the tool used to establish the scope of any given case. ${ }^{3}$

A theory of harm to citizen wellbeing instead points us towards the institutions required to exercise civic duties and maintain the collective society, and therefore can delineate an integrated platform ecosystem case. Here we advance a theory of harm to citizens, as individuals and as collective publics, from the loss of mass audiovisual media due to competition from online content delivery platforms. The key concern is the potential that platform dominance on the playing field for advertising is detrimental to the advertising-supported audiovisual media.

There is ample evidence that the thriving online content delivery platforms have become crucial locations for individual expression, disseminating information and political organising, especially for minorities and vulnerable groups, but not necessarily a shared experience or public sphere (Papacharissi, 2010). They can also be used to spread misogyny, racism and xenophobia, with women and people from minority backgrounds sometimes silenced by threats and abuse. Audiovisual media services, which in Europe include many public service broadcasters, are still the biggest investors in content, attract mass audiences, and in most jurisdictions remain heavily regulated. Concerns have been raised about the impact of these declining revenues on the production of journalism (Australian Competition and Consumer Commission, 2018; Bell, 2018; Cairncross, 2019). Journalism is widely acknowledged to be important for the exercise of democracy in multiple ways, but the normative standpoint behind our theory of harm is not only concerned about journalism.

Entertainment content, the mass consumed foundation of popular culture, is important for social cohesion and democracy (Street, 2010). Though it can serve to 
perpetuate stereotypes and inequalities, mass entertainment content also provides space where societies can negotiate new norms, as exemplified by its role in mainstreaming diversity in gender identity and sexual orientation (Calzo \& Ward, 2009; Bonds-Raacke 2007). A diversity of content is required for media to fulfil its role in enabling individuals' expression rights and self-actualisation (Baker, 1989). Societies need a pluralism of institutional forms, owners, and political and cultural purposes in order to ensure citizens can exercise rights fundamental to their wellbeing (Baker, 2006; Kenyon, 2014) both as individuals and as collectives. They need both platforms through which they can share their own content and engage with that of others, and a diversity of media companies with sufficient scale to invest in quality mass-consumed professional content.

The expansion of content sharing platforms such as Facebook and YouTube, and the growth of programmatic means for buying online inventory on websites has resulted in rapid growth in online advertising, especially online video (IAB Europe, 2019; Zenith Media, 2019). In the meantime, revenues for audiovisual media services (television) have been nearly stagnant and print media have suffered enormously (Zenith Media, 2019, p. 9). Recent policy debates about how to achieve a more level playing field between online platforms and audiovisual media services were central to recent revisions to EU media laws (Broughton Micova, forthcoming). One of the main steps taken was to even out qualitative rules related to advertising. Competition authorities have also been investigating online advertising and found problematic platform dominance (e.g., Australian Competition and Consumer Commission, 2019; Competition \& Markets Authority (CMA), 2020). There is, therefore, a well-established normative basis for this theory of harm to citizen wellbeing and some indications that harm may be occurring.

\section{Methodology}

The starting point for this investigation was the theory of harm to citizens and society as a result of fewer resources going into the mass media. It was inspired by debates about the extent to which online platforms were competing with audiovisual media services for advertising and claims that this competition was not fair. Though there was evidence of declining or stagnating revenues, we did not assume these declines were a result of unfair advantage or platform dominance, but neither did we assume that firms selling online advertising inventory or carrying user generated content were operating in separately defined markets from audiovisual media services. Instead, we set out to uncover the dynamics of what we initially termed a playing field delineated by our theory of harm. Our mapping of 
players and relationships based on this theory of harm resulted in an ecosystem that included multiple online platforms and various actors, private and public firms, that engage in the supply of content to audiences/users and the trade in the video advertising that supports it.

The ecosystem-based framework calls for nuanced understanding of the dynamics among the firms within this ecosystem and the conditions that shape them more than economic assessments of relative position and performance. We sought answers to questions about how relationships among the firms were formed and maintained and how decisions were made in relation to the transactions among them. This required talking to those nurturing the relationships and making decisions within the firms, which we did through semi-structured interviews. To understand the conditions within which this was happening we conducted an analysis of regulatory frameworks and examined academic and trade publications, as well as documents produced by the firms involved, for evidence on business conditions and practices.

Advertising still happens very much on national levels, so we needed to designate national jurisdictions to serve as a sample of the conditions within which actors were operating. We wanted to engage with actors in relatively developed markets where the main global players have a presence, ${ }^{4}$ whilst ensuring some diversity of experience. We chose to approach individuals representing actors in Belgium, France, Italy and the UK to achieve a mix in the ratio of online to offline advertising expenditures and in the development of programmatic and other addressable advertising options. As EU member states, all four shared significant regulatory commonalities at that time. However, since the area of media is characterised by minimum harmonisation and devolved competencies, the four countries also offered some variety in regulatory frameworks. Data available at the time showed that the UK, Italy and France were amongst the biggest TV advertising markets in the EU, but the UK far exceeded the others in the use of online, particularly programmatic, advertising (Grece, 2017). TV revenues were growing still only in Italy. Belgium was taken as a smaller market with its own intricacies due to the devolution of powers to its communities and the use of French, Flemish and German as national languages. In every country scrutinised, television advertising remained an important component of media planning, although to different degrees. London, Paris and Milan were also all locations where individuals with regional re-

4. We considered including additionally a smaller country from South Eastern Europe where we also would have had linguistic competence, but there was limited in-country presence of major platforms and the budgets of major advertisers were often set at a regional level. 
sponsibilities were located, and several of those interviewed were not solely responsible for national markets.

We conducted 26 'elite' semi-structured interviews (Aberbach \& Rockman, 2002; Harvey, 2011) with 36 respondents in total - from advertisers, media agencies, video sharing platforms, to audiovisual media services. These were mostly conducted with senior persons included for their key role in the decision-making and their responsibility for relationships between actors, while three would qualify as 'expert' interviews with individuals not directly involved in the trade (Van Audenhove \& Donders, 2019). ${ }^{5}$ A two layered thematic coding of interview transcripts was done using Nvivo. The first layer of coding was based on the interview responses about how budget expenditure and media buying decisions were made on the demand side, how supply side actors sold their inventory and set prices, how metrics or and data were used, and the nature of the relationships among the players. In the second layer of coding, themes identified in the first layer were mapped out in a spreadsheet, and the word frequency functions within Nvivo were used to help confirm salience and identify themes. ${ }^{6}$

The regulatory frameworks in the four countries were examined through a set of pre-determined variables, based on what the literature and interview data indicated shaped the conditions for the ecosystem. We looked at legislation, regulatory decisions, and self-regulatory instruments in the following areas: consumer protection (in relation to advertising), data protection, taxation (as applicable to the relevant companies), competition and pluralism, advertising standards and content rules. A detailed presentation of the empirical work was published as a policy paper (Broughton Micova \& Jacques, 2019) intended for policy makers and stakeholders, and covered issues of substitutability of ad inventory, data use, the evenness of rules and relationships among actors. Our interrogation of the data from the perspective of platform power forms the basis for the findings we present here.

5. Sampling was purposive with individuals identified through industry contacts and by trawling through corporate web pages and Linkedln profiles. Interviews were conducted between 1 August and 20 October 2018, mostly individual, but sometimes with responsible teams, hence the difference between the number of interviews and the number of interviewees. Though we were unable to get representatives from all the major global platforms to agree to participate, we did get a mix of three different firms with different profiles in terms of involvement in the ecosystem. Those interviews with actors outside of the actual trade came from one regulatory authority, one commercial insight firm, and one pan-European industry association.

6. Sixty-eight sub-codes were identified across the first level themes. To be included a sub-theme had to be found in at least two transcripts. A full matrix is available from the authors. 


\section{The video advertising ecosystem}

In this section we explain the integrated platform ecosystem for audiovisual advertising as understood through the application of our framework and built on our empirical data. The findings indicate that relationships beyond the direct exchange of money or data among actors, even personal connections between individuals, remain crucial, with a variety of resources required for the maintenance of those relationships. We found two systemic sources of strategic power:

- Relationship advantage (stemming from transnational nature and large scale)

- Opacity bias (stemming from lack of transparency in trading systems)

Before elaborating these systemic conditions that seemed to contribute to accumulation of strategic power, we first describe the actors involved in the ecosystem, illustrated in Figure 1 below, and the relationships among them.

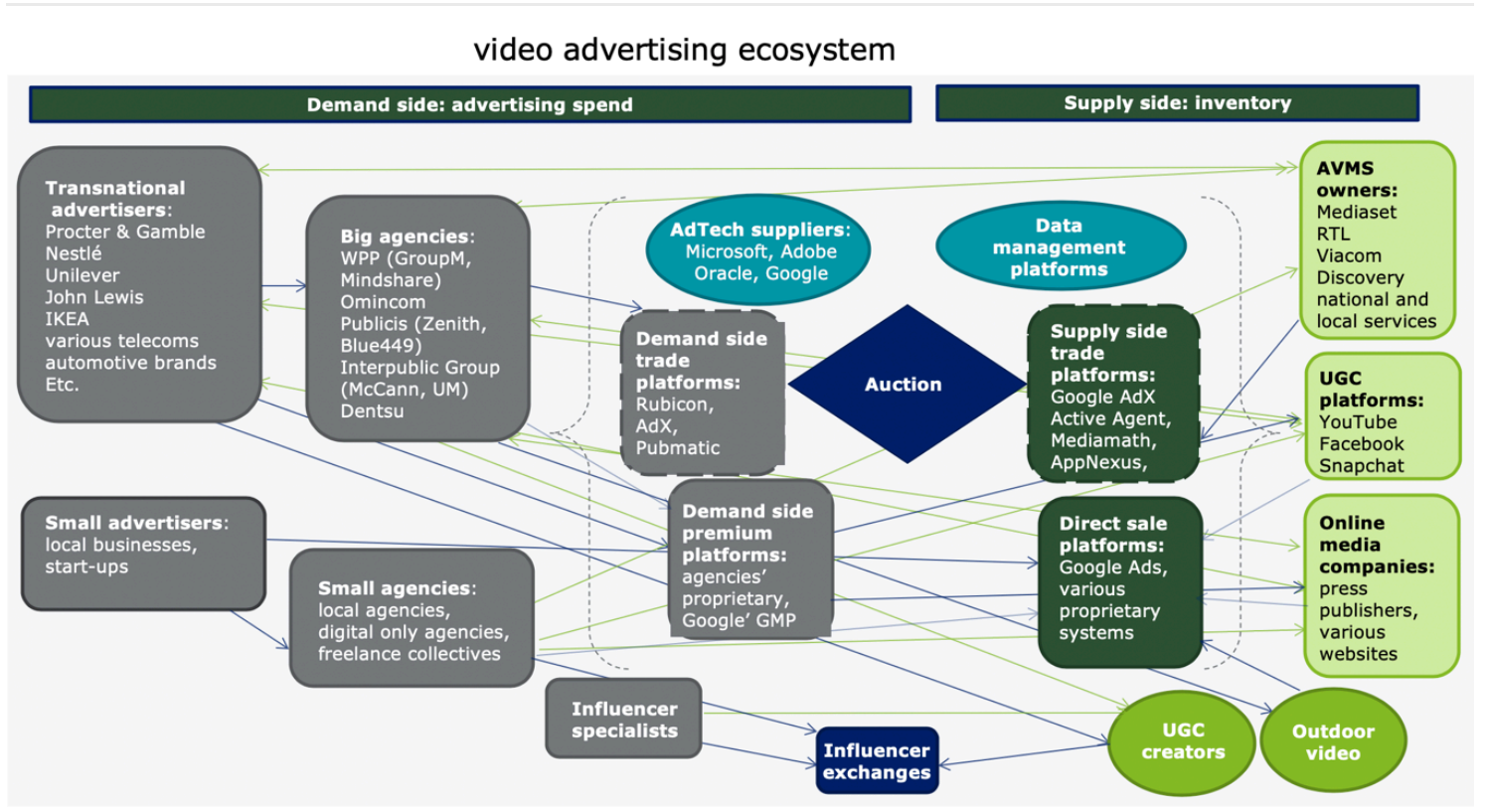

FIGURE 1: Integrated platform ecosystem for video advertising. Source: The authors, adapted and advanced from an earlier version in Broughton Micova \& Jacques, 2019 p. 9

Figure 1 shows a picture of complexity and interconnectedness. Separated into demand side (grey) and supply side (green), it shows the main categories of actors. Our investigation affirms the elaboration of the flows of money and data among those involved in online advertising given by Adshead and colleagues (2019), but also reveals the importance of relationships that often do not involve the direct exchange of money or data, indicated here by the bright green lines. These can crucially shape the conditions of transactions and decisions regarding spending. 
On the right-hand side of Figure 1 are those that offer video advertising inventory. The audiovisual media services offer a variety of inventory on linear television and on their video on demand (AVOD) services, as well addressable options on TV and their websites that can be sold directly or through programmatic trading. Programmatic trading, which is indicated by the bracketed area in Figure 1, is the trading of advertising through automated means using multiple data points. It can be through real time bidding (RTB) shown in the 'auction' diamond or by non-auction means that are still automated, which we have indicated by dark blue lines of exchange between reserve platforms (for a fuller explanation see IAB Europe, 2014). The platforms for user-generated content (UGC) such as YouTube (Google) and Facebook sell programmatically through both RTB and reserve systems, in which premium inventory is sold through non-auction marketplaces. Press publishers and countless websites also offer video advertising, a lot of which is traded programmatically through RTB, with only the larger ones having premium buy or other direct sales options.

On the left side of Figure 1 are the demand side actors, or those that hold the advertising budgets and are buying advertising inventory divided between large companies that operate across multiple national markets and ones that operate mainly within a national market. A consistent message from those interviewed was that most decision-making about campaign strategy and planning was still largely done within national markets. However, a growing trend towards internationalisation was reported to exist among the large multi-national advertisers, coupled with an increasing focus on short-term performance driven by elevated roles for procurement and finance within the advertisers. Those on the supply side that operate transnationally and can build the kind of non-transaction relationships shown by the bright green lines in Figure 1 with advertiser headquarters seemed to have an advantage over those that do not.

\section{Relationship advantage: building ties and faith in the channel}

Platform and audiovisual media services (AVMS) respondents reported spending vast amounts of time and resources on "client support", developing trust and personal relationships as well as educating agencies and advertisers about their tools and the value of their inventory. Larger businesses with greater resources to invest in this kind of relationship building would have an advantage. One platform respondent described, "at least the first couple years were just on educating, and there were small teams within all agencies that taught about programmatic and how to bring programmatic products to agencies". In contrast, a respondent from a national level AVMS reported his company had a team of two people traveling 
around to advertisers explaining what could be done with the addressable TV that they were rolling out.

In addition, at a global level, large advertisers have, as one respondent described, "deep direct relationships" with all the major inventory holding platforms as well as ad tech suppliers and demand side platforms (DSPs) through which buying takes place. One respondent from a major advertiser explained that these allow them to deal with issues such as brand safety and environment quality. Another put it in terms of establishing "global principles and best practices" for working with them. It was mentioned that large platforms had made great improvements on brand safety tools, and there are third party verifying tools. One respondent from a global portfolio brand claimed that threats from advertisers to pull their campaigns had led to some of the brand safety improvements on major platforms such as YouTube, but when asked if that meant they were in a position of strength, he responded: "I don't think anybody is in a position of strength against Google...because they are so dominant and very, very smart".

The inventory offered by AVMS was already trusted in terms of brand safety and environment, but AVMS respondents consistently reported having to convince agency and advertiser contacts of the effectiveness of their inventory. They also reported working through their transnational associations or in smaller collaborations to reassure advertisers of the effectiveness of their inventory. This included investing in their own programmatic tools for trading across services and even transnationally in order to meet advertisers needs for addressability (e.g., Dziadul, 2019; EBX, 2017). Nevertheless, they appeared at a disadvantage not only because of differences in the resources available for investment but also in the accessibility of the data required for telling the story of success, which will be discussed further in the section below. AVMSs appeared to be vying not just market power, but instead, we argue, a form of strategic power that seems to stem not just from the size of a platform's user base or audience but also from its capacity to invest in personal relationships and building faith in its inventory and tools, as well as the transnational level at which some relationships operated.

\section{Opacity bias: lack of transparency enhancing power}

The direct close relationships the inventory holders have with advertisers shape the preferences and perceptions of effectiveness that feed into the negotiations that agencies have in the buying process. It was confirmed by respondents of all categories that the rebates, discounts and kickbacks for which the arbitrage system of media buying has been known are still prevalent, despite the growth of pro- 
grammatic trading. Numerous respondents from demand and supply sides cited the lack of transparency in the exchanges involved the buying of addressable inventory, especially through programmatic trading, as a source of concern and even mistrust.

The volume discounts or rebates negotiated between agencies and AVMSs were reported to be somewhat transparent in the countries studied because of the audited and accessible audience measurement and regulation requiring financial reporting. However, this was not the case in relation to platforms and online inventory. As has been noted also in other reports (Adshead et al., 2019; Select Committee on Communications, 2018; Stigler Center, 2019) there is a severe lack of transparency in the dealings that occur in the middle of Figure 1 where programmatic trading and premium buys of online inventory takes place. Multiple agency respondents acknowledged they often get high margins on this kind of trading. Some attributed a preference for it to the erosion of agency commissions and pressures to reduce fees.

The financial exchanges were not the only issue. In premium and reserve buying other conditions such as placement, brand safety protection and other qualitative considerations were mentioned as important parts of deals. Complex tools and specific expertise are required to navigate the online buying environment. Things change frequently and the evidence from respondents representing demand side actors indicated that media agencies have positioned themselves as able to keep up with the dynamic and complex online buying environment. According to multiple agency respondents, they were not able to control all the conditions, such as what viewability and duration will count as a chargeable view, but they invested a great deal in expertise to get the most out of buying online inventory. Their accounts attested to the ability of platforms to set the terms of trade for complementors (Kenney et al., 2019; Schreieck et al., 2016). The accounts also indicate that the capacity to navigate the technology created by platforms were of strategic value to the agencies.

Examining the integrated platform ecosystem shows that there is also power in being able to work effectively across those individual ecosystems. There is not one firm responsible for the lack of financial, and contractual, transparency in the trading of online inventory but it does appear to be a source of strategic power, for media agencies as well as online platform owners. The implications of this opacity are not only that national and local media be harmed if agencies are incentivised to push programmatic online options to clients, but also citizen wellbeing can be diminished in other ways given the evidence of discrimination, gender stereotyp- 
ing and other negative aspects of targeted online advertising (Boi et al., 2020; Andreou et al., 2019; Speicher et al., 2018).

\section{Systemic sources of strategic power}

The evidence above indicates that firms with larger capital resources operating transnationally and those whose inventory allows media agencies to extract larger margins due to the lack of transparency in trades, have greater strategic power in the ecosystem. The one exception among the cases was in France, where the Sapin Law - in place since 1993 - ensured that financial details such as actual cost, discounts and agency margins were shared with agencies. Amendments in 2015 and 2017 extended its reach to online advertising giving advertisers access to details on bid and traded prices as well as qualitative conditions for programmatically traded inventory. This fills to some extent the informational gaps, allowing advertisers to understand the true costs of various inventory and removing some of the incentives for media agencies to choose programmatically traded inventory. It does not reduce the need for specialist expertise through which agencies derive some power.

The provision of the data to advertisers as mandated by the Sapin Law also does not equate to the same level of transparency in the whole system afforded by the combination of independent and audited audience metrics and regular financial reporting characteristic of AVMSs. The consequence is that not all those working to build relationships with advertisers and faith in their inventory are able to develop the same insight into their competition and assess the relative value of their offer. This problem is exacerbated by the way data functions and flows in the ecosystem.

\section{Power at nodes of data use}

Data flows along many of the lines illustrated in Figure 1 above, but these flows are characterised by vast differences in the ability to generate and access data as well as lock-in effects. Personal data enables the targeting of individuals and households. It comes together from a variety of sources in media agencies and most crucially in the platforms used to "activate" campaigns online. Van Dijck et al. (2019), suggest looking for nodes of infrastructural power within an integrated platform ecosystem.

We identified three nodes of data use within the ecosystem where there appear to be imbalances in infrastructural and strategic power: 
- Targeting node (where ads are served to individuals)

- Planning node (where potential effectiveness is determined)

- Metrics node (where past efficiency is demonstrated)

At the targeting node personal identifiable data functions in the delivery of online ads to specific users based on targeting criteria. At the planning and metrics nodes, personal data that has been pseudonymised or possibly anonymised such that it could be considered non-personal (Article 29 Data Protection Working Party, 2014), and non-personal data generated by financial transactions enable decision making.

\section{Targeting node: walled gardens of personal data}

Eight different respondents used the term "walled gardens" to describe where data flows are contained and controlled by individual companies, sometimes owning multiple platforms at different places in the ecosystem. One interviewee described the problem with walled gardens as being that they bind them into using a particular platform for placing ads even across a variety of inventory holders. As was explained by interviewees from platforms, containing personal data within their individual platform ecosystem is necessary to comply with data protection rules, which they saw not just as a legal obligation but also as duty to their users. Maintaining walled gardens may be completely justifiable on data protection grounds. Nevertheless, this point where the personal data used in targeting is linked to specific individuals being served ads seems to be a crucial node where power is accumulated in the ecosystem.

Here, the distinction made by van Dijck et al. (2018) between infrastructural and sectoral platforms is useful. Those platforms in the ecosystem that connect the ad to the individual, using his or her personal data, could be considered infrastructural in the same way as telecommunications networks (digital terrestrial television, cable, internet protocol television, satellite) used to deliver ads to audiences in television channels. The online platforms delivering the content in which the ads are placed, such as YouTube or Facebook, can be considered sectoral platforms, parallel to the audiovisual media services whose channels provide the vehicle for the ads served to television audiences.

Some walled gardens are bigger than others and many sectoral platform owners also own infrastructural ones. The evidence from the interviews indicates that there is an imbalance in infrastructural power with some infrastructural platforms, namely those owned by Alphabet/Google, overwhelmingly most used because of the amount of personal data in their garden (for an ownership analysis of adserv- 
ing see Geradin \& Katsifis, 2019). For example, in the accounts from agency respondents it appeared that it was not that YouTube as a medium was unavoidable, but that the Google-owned tools for buying online inventory were. Google and Facebook were not the only actors holding some of that kind of power, however. Media agencies played a pivotal role in the accumulation and utilisation of personal data, including from third party providers and from their clients - and some also owned platforms engaged in the node described above. Audiovisual media services were emulating the "walled gardens" model for their addressable options. One interviewee stated that data ownership was a key issue in their agreement with the network operator in their roll out of addressable TV, ${ }^{7}$ whereas in another jurisdiction this was regulated by law.

\section{Planning \& metrics nodes: functions of aggregate and anonymised data}

We found a different kind of power at play in the planning node, where decisions were made by those controlling advertising budgets. Here strategic power seemed to stem from the ability to pool and use data generated by users' behaviour and past campaigns in aggregate form, that is akin to the panel surveys and audience measurement data that have long been used in advertising. Multiple agency respondents described using complex econometric models in campaign design, as "a directional tool". Historical data linked to past campaigns and generated by user behaviour also feeds into attribution models and other means for demonstrating the efficacy of various inventory options in achieving certain objectives. The cost of inventory also figures into both designing campaigns and in demonstrating success.

A crucial source of advantage was evident in the ability to join up data from past financial transactions with the aggregate user or audience data. Here, media agencies seem to have the most access to input data and the capacity to process it. Several media agency respondents explained that they consider video as a whole now rather offline and online separately, but that this required effort and expertise due to the lack of standardisation of metrics. The lack of a "common video currency", which was mentioned by many respondents from various actors in the ecosystem, and the "walled gardens" made it difficult for the agencies to, as one respondent put it, "join up" across inventory holders even though this kind of data could be sufficiently anonymised as to no longer be personal.

7. Addressable TV refers to a way of delivering targeted advertising to households during linear TV broadcasting. 
It was in the metrics node of demonstrating efficacy and efficiency that the aggregate data generated by people's behaviour online appeared to function in the same way as the much more accessible and independently audited audience measurement data used for television. Some firms were better represented in these metrics and had the ability to shape them. Here, the scale of an actor's strategic power therefore can be determined by the extent to which they have access to the necessary aggregate data and/or the ability to set the terms upon which success is determined. This aggregate data could be considered essential for competition among advertising dependent media. If, as set out in the theory of harm elaborated above, a plurality of independent media is important to citizen wellbeing, then ensuring access to and auditing of metrics is essential to a healthy ecosystem and defendable on public interest grounds.

\section{Collecting information at nodes of power}

Numerous options are on the table for dealing with the perceived dominance of certain platforms, including breaking up companies, mandating data sharing or openness, sector specific regulation, and other structural remedies. As Rahman has pointed out, in considering any kind of structural regulation of platforms, "the conceptual challenge we face now is precisely over the question of what kinds of information to collect, control, and pursue" (2018, p. 250). We found that a distinct value of examining an integrated platform ecosystem bound by a specific theory of harm, is that the identification of types and nodes of power can indicate what information is necessary to inform regulatory intervention. The evidence from this investigation indicated that infrastructural and strategic power is concentrated in online platform owners, especially the ones owning multiple platforms within the ecosystem. However, it also showed that in some nodes other actors also have power. Media agencies hold power in the generation of insight from data for predicting the potential efficacy of inventory. AVMSs, may be gaining power in the infrastructural targeting node where aggregate insight is joined with personal data for targeting. What information must be collected or pursued in order to determine when intervention is needed and of what kind?

TABLE 1: Three nodes of power stemming from the function of data and the related information

NODE

Targeting node: where insight is joined with personal data for serving ads Source: the authors

\section{INFORMATION}

The number of platforms engaged in exactly this node, who owns them and 


\begin{tabular}{|c|c|}
\hline NODE & INFORMATION \\
\hline (infrastructural) & $\begin{array}{l}\text { their share of the trade;The extent to } \\
\text { which the software and channels } \\
\text { required are proprietary or open;The } \\
\text { extent to which media buyers and } \\
\text { advertisers have a choice among ways } \\
\text { to serve advertising or inventory } \\
\text { holders have a choice through which to } \\
\text { supply; The extent to which media } \\
\text { buyers and advertisers on one side and } \\
\text { inventory holders on the other side are } \\
\text { able to influence the conditions of the } \\
\text { contracts with the platforms active in } \\
\text { this node. }\end{array}$ \\
\hline $\begin{array}{l}\text { Planning node: where aggregate data } \\
\text { from multiple sources is used to } \\
\text { determine how effective various } \\
\text { inventory are likely to be to reach an } \\
\text { objective (strategic) }\end{array}$ & $\begin{array}{l}\text { The point at which personal data from } \\
\text { people's behaviour online or } \\
\text { volunteered by them become non- } \\
\text { personal - the level and location of } \\
\text { anonymisation and aggregation;The } \\
\text { number of different actors engaged in } \\
\text { this node, who owns them, and their } \\
\text { share of trade;The extent to which the } \\
\text { actors selling inventory are } \\
\text { represented in the data used and the } \\
\text { extent to which they have a view to } \\
\text { how they are represented. }\end{array}$ \\
\hline $\begin{array}{l}\text { Metrics node: where aggregate data is } \\
\text { used to generate metrics for } \\
\text { demonstrating effectiveness and } \\
\text { efficiency (strategic) }\end{array}$ & $\begin{array}{l}\text { The point at which personal data from } \\
\text { people's behaviour online or } \\
\text { volunteered by them become non- } \\
\text { personal - the level and location of } \\
\text { anonymisation and aggregation; The } \\
\text { sources of the data required to } \\
\text { generate the metrics used and who has } \\
\text { access to that data;The way the metrics } \\
\text { have been defined and the actors that } \\
\text { have been involved in doing it; The } \\
\text { extent to which the metrics are } \\
\text { transparent or accessible to all actors. }\end{array}$ \\
\hline
\end{tabular}

Source: the authors

Some of the types of information listed in Table 1 are ones that are typical of com- 
petition market studies such as the share of trade of each actor or the extent to which there is a choice of firms to use. The information we suggest be gathered in relation to the targeting node should contribute to an evaluation of any gatekeeping (Lynskey, 2017). It can help to establish whether the gatekeeping amounts to a problematic form of dominance and the extent to which it is necessitated by data protection law or a result of certain platforms' artifactual and contractual governance of others in their ecosystems (Kenney et al., 2019). A key step noted for the planning and metrics nodes is the assessment of where and how the personal data gathered by the various actors in the ecosystem no longer needs to be personal, or when it is aggregated and anonymised to an extent that no longer requires protection. This step seems a necessary precursor to any intervention aimed at pro-competition regulation related to data sharing or openness. This may involve data from platforms, AVMSs with addressable options, network providers, device makers, and various third-party data providers and trackers. The types of information required to uncover potential dominance or undue power in the metrics node are directly related to the participation in the integrated ecosystem of platforms that exercise control over standards within their individual ecosystems (Schreieck et al., 2016). This is where the individual platform ecosystems they control interact with audiovisual media services and other players for which there are industry-wide independent measures of success.

\section{Conclusion}

In this article we put forth a theory of harm to citizen wellbeing and used it to define a specific integrated platform ecosystem creating an operational framework for assessing platform power. Our theory of harm from the loss of mass media draws on normative understandings of the role of mass media and online platforms in enabling the exercise of individual and collective expression rights. While online content sharing platforms are important in many ways, there is a risk of harm to citizen wellbeing from a loss of the mass media that invest in audiovisual content, much of which is advertising supported. Dominance or problematic concentrations of power can result in unfair competition for advertising that threatens the long-term viability of other advertising dependent media. A loss of advertising supported audiovisual media services could reduce citizens' access to information and representation, and to content that enables the negotiation of shared norms and collective identities. Citizens' expression can be limited if they do not have alternatives to highly personalised media. The specific integrated platform ecosystem we examined was therefore defined so as to include the businesses involved in the delivery of audiovisual content to citizens and the trade in the advertising 
around it.

The evidence presented here points to disproportionate power or dominance by the companies that own multiple platforms at different parts of the ecosystem. Firstly, we identified sources of strategic power stemming from structural conditions within this ecosystem. Global companies with vast resources to invest in building relationships and faith in what they offer compete with national and local companies. There is also a wide-reaching lack of transparency in the trade in online advertising inventory. The evidence we presented above supports calls for greater transparency in the trading of online inventory. The model of the French Sapin Law is a useful starting point. Secondly, we found three nodes where both personal and non-personal data function within this ecosystem and where it appeared infrastructural and strategic power are accumulated. Not all power was in the hands of online platforms, however.

For each of these nodes we outline specific information that would help regulators determine if this accumulation results in problematic dominance. At the infrastructural targeting node, pursuing the information we suggest should inform debates about whether some of the infrastructural platforms involved in the advertising trade should be regulated as public utilities (Sabeel Rahman, 2018), deemed to have "strategic market status" (Furman et al., 2019), or perhaps even be separated from owners that also sell inventory (Warren, 2019). At the planning node, a strategic one in which the effectiveness of inventory is determined, the evidence we presented above suggests that large media agencies feature significantly in the distribution of power. However, more information on the firms involved and how they are represented in the data used at this node would be needed to identify any unhealthy imbalance in that distribution. At the metrics node, we argue that precise investigation into the way metrics are defined and the accessibility of that process could provide justification for the non-personal data involved to be deemed a public resource (Napoli, 2019), or for other means of encouraging or enforcing data openness. Information gathering and assessment at these nodes will likely require the powers to elicit information held by regulators.

This investigation looked only at one specific integrated platform ecosystem. The largest platform owning companies involved in this ecosystem are also involved in others. If the theory of harm used was grounded more in concerns about employment opportunities and other benefits of a healthy creative sector rather than expression rights and citizenship, it would likely have involved a different set of nonplatform actors such as independent production companies and rights holders. The power of major platform owning companies is likely to be nuanced and vary across 
integrated platform ecosystem cases. Looking at multiple ones guided by theories of harm grounded in understandings of the public interest can contribute to a holistic platform policy that avoids knee-jerk reactions. We look forward to seeing other specific cases studied. We suspect that both infrastructural and strategic power could be found in ecosystems defined by theories of harm to citizens, societies, and local business from platform engagement with smart cities, or by theories of harm to businesses and labourers from platforms engaged in e-commerce, or by many others derived from citizen wellbeing concerns.

\section{ACKNOWLEDGEMENTS}

This article is based on empirical work conducted for The Playing field for audiovisual advertising: What does it look like and who is playing, a study written for the Centre on Regulation in Europe (CERRE, www.cerre.eu), accessible at https://cerre.eu/sites/cerre/files/ cerre_playingfieldaudiovisualadvertising_2019april.pdf. The study and this article reflect the views of the authors only; it may not reflect the view of CERRE or its members. The authors thank CERRE for its support of the original investigation and colleagues within CERRE for the fruitful discussions around its findings that contributed to the further analysis reflected in this article. The authors also thank Felix Hempel for research assistance during the investigation as well as Damian Tambini, Toby James, Mayo Fuster Morell, Frédéric Dubois, Andrej Savin and Matthias C. Kettemann who thoughtfully reviewed earlier drafts.

\section{References}

Abate, S. (2018). Antitrust and consumer enforcement in data markets-Are new theories of harm based on privacy degradation hitting the mark? 29th European Regional ITS Conference, Trento.

Aberbach, J. D., \& Rockman, B. A. (2002). Conducting and coding elite interviews. PS: Political Science \& Politics, 35(4), 673-676. https://doi.org/10.1017/S1049096502001142

Adshead, S., Forsyth, G., Wood, S., \& Wilkenson, L. (2019). Online Advertising in the UK [Report]. Plum Consulting. https://assets.publishing.service.gov.uk/government/uploads/system/uploads/atta chment_data/file/777996/Plum_DCMS_Online_Advertising_in_the_UK.pdf

Anderson, S. P., \& Jullien, B. (2015). The Advertising-Financed Business Model in Two-Sided Media Markets. In Handbook of Media Economics (Vol. 1A, pp. 41-90). Elsevier. https://doi.org/10.1016/B97 $\underline{8-0-444-62721-6.00002-0}$

Andreou, A., Silva, M., Benevenuto, F., Goga, O., Loiseau, P., \& Mislove, A. (2019). Measuring the Facebook Advertising Ecosystem. Network and Distributed Systems Security Symposium, San Diego. $\underline{\mathrm{h}}$ ttps://doi.org/10.14722/ndss.2019.23280 
Article 29 Data Protection Working Party. (2014). Opinion 05/2014 on Anonymisation Techniques. European Commission. https://ec.europa.eu/justice/article-29/documentation/opinion-recommenda tion/files/2014/wp216_en.pdf

Australian Competition and Consumer Commission. (2018). Digital Platforms Inquiry: A preliminary report [Report]. Australian Competition and Consumer Commission.

Australian Competition and Consumer Commission. (2019). Digital Platforms Inquiry: Final report [Report]. Australian Competition and Consumer Commission. https://www.accc.gov.au/system/files/ Digital\%20platforms\%20inquiry\%20-\%20final\%20report.pdf

Baker, C. E. (1989). Human liberty and freedom of speech. Oxford University Press.

Baker, C. E. (2006). Media concentration and democracy: Why ownership matters. Cambridge University Press.

Bamberger, K. A., \& Lobel, O. (2018). Platform Market Power. Berkeley Technology Law Journal, 32(3), 1051.

Bell, E. (2018). The Dependent Press: How Silicon Valley Threatens Independent Journalism. In M. Moore \& D. Tambini (Eds.), Digital Dominance: The Power of Google Amazon Facebok and Apple. Oxford University Press.

Bol, N., Strycharz, J., Helberger, N., Velde, B., \& Vreese, C. H. (2020). Vulnerability in a tracked society: Combining tracking and survey data to understand who gets targeted with what content. New Media \& Society, 22(11), 1996-2017. https://doi.org/10.1177/1461444820924631

Boudreau, K. J., \& Hagiu, A. (2009). Platform rules:multisided platforms as regulators. In A. Gawer (Ed.), Platforms, Markets and Innovation. Edward Elgar Pub.

Broos, S., \& Marcos Ramos, J. (2017). Google, Google Shopping and Amazon: The Importance of Competing Business Models and Two-Sided Intermediaries in Defining Relevant Markets. The Antitrust Bulletin, 62(2).

Broughton Micova, S. (forthcoming). The Audiovisual Media Services Directive: Balancing liberalisation and protection. In E. Brogi \& P. L. Parcu (Eds.), Handbook on EU Media Law and Policy. Edward Elgar Publishing.

Broughton Micova, S., Hempel, F., \& Jacques, S. (2018). Protecting Europe's content production from US giants. Journal of Media Law, 10(2), 219-243. https://doi.org/10.1080/17577632.2019.1579296

Broughton Micova, S., \& Jacques, S. (2019). The Playing field for audiovisual advertising: What does it look like and who is playing [Report]. Centre on Regulation in Europe. https://cerre.eu/publications/p laying-field-audiovisual-advertising/

Buttà, A. (2018). Google Search (Shopping): An Overview of the European Commission's Antitrust Case. Antitrust \& Public Policies, 5(1). https://doi.org/10.12870/iar-12872

Cairncross, D. F. (2019). The Cairncross Review: A sustainable future for journalism [Policy paper]. UK Department of Media Culture and Sport. https://www.gov.uk/government/publications/the-cairncro ss-review-a-sustainable-future-for-journalism

Calzo, J. P., \& Ward, L. M. (2009). Media Exposure and Viewers' Attitudes Toward Homosexuality: Evidence for Mainstreaming or Resonance? Journal of Broadcasting \& Electronic Media, 53(2). http s://doi.org/10.1080/08838150902908049 
Castells, M. (2011). Network theory. A network theory of power. International Journal of Communication, 5, 15.

Castells, M. (2013). Communication power. Oxford University Press.

Caves, K. W., \& Singer, H. J. (2018). When the Econometrician Shrugged: Identifying and Plugging Gaps in the Consumer Welfare Standard. George Mason Law Review, 26(2), 395-425. http://georgem asonlawreview.org/wp-content/uploads/2019/10/3.-CavesSinger_Final.pdf

Competition \& Markets Authority. (2020). Online platforms and digital advertising: Market study final report [Report]. Competition \& Markets Authority. https://assets.publishing.service.gov.uk/media/5ef c57ed3a6f4023d242ed56/Final_report_1_July_2020.pdf

Coyle, D. (2018a). Platform Dominance: The shortcomings of anti-trust policy. In M. Moore \& D. Tambini (Eds.), Digital Dominance: The Power of Google, Amazon, Facebook and Apple. Oxford University Press.

Coyle, D. (2018b). Practical competition policy implications of digital platforms (Working Paper No. 01/ 2018). University of Cambridge, Bennett Institute for Public Policy. https://www.bennettinstitute.ca m.ac.uk/media/uploads/files/Practical_competition_policy_tools_for_digital_platforms.pdf

Crémer, J., Montjoye, Y.-A., \& Schwitzer, H. (2019). Competition Policy for the Digital Era (Report KD-04-19-345-EN-N). Publications Office of the European Union. http://doi.org/10.2763/407537

Dijck, J., Nieborg, D., \& Poell, T. (2019). Reframing platform power. Internet Policy Review, 8(2). http s://doi.org/10.14763/2019.2.1414

Dijck, J., Poell, T., \& de Waal, M. (2018). The Platform Society. Oxford University Press. https://doi.or g/10.1093/oso/9780190889760.001.0001

Dziadul, C. (2019, June 5). RTL and ProSiebenSat.1 ink addressable TV joint venture. Broadband TV News. https://www.broadbandtvnews.com/2019/06/05/prosiebensat-1-rtl-ink-addressable-tv-jointventure/

E.B.X. (2017, September 11). European Media Corporations Agree on Joint Venture [Press release]. European Broadcasting Exchange, Press Room. http://ebx.tv/?p=314

European Commission. (1997). COMMISSION NOTICE on the definition of relevant market for the purposes of Community competition law 97/C 372/03). Official Journal of the European Communities. https://eur-lex.europa.eu/legal-content/EN/TXT/PDF/?uri=CELEX:31997Y1209(01)\&from=EN

European Commission. (2017a). Antitrust: Commission fines Google €2.42 billion for abusing dominance as search engine by giving illegal advantage to own comparison shopping service [Press release]. European Commission, Press Corner. https://ec.europa.eu/commission/presscorner/detail/e n/IP 171784

European Commission. (2017b). Mergers: Commission fines Facebook $€ 110$ million for providing misleading information about WhatsApp takeover [Press release]. European Commission, Press Corner. https://ec.europa.eu/commission/presscorner/detail/en/IP_17_1369

European Commission. (2019). Antitrust: Commission fines Google $€ 1.49$ billion for abusive practices in online advertising [Press release]. European Commission, Press Corner. https://ec.europa.eu/commiss ion/presscorner/detail/en/IP_19_1770

Evans, D. S. (2003). The Antitrust Economics of Multi-Sided Platform Markets. Yale Journal on Regulation, 20(2). https://digitalcommons.law.yale.edu/cgi/viewcontent.cgi?referer=https://scholar.g 
oogle.co.uk/\&httpsredir=1\&article=1144\&context=yjreg

Evans, D. S., \& Schmalensee, R. (2013). The Anti-trust analysis of multi-sided platform business (Working Paper No. 18783). National Bureau of Economic Research.

Furman, J., Coyle, D., Fletcher, A., Marsden, P., \& McAuley, D. (2019). Unlocking Digital Competition: Report of the Digital Competition Expert Panel [Report]. HM Treasury.

Geradin, D., \& Katsifis, D. (2019). Google's (Forgotten) Monopoly - Ad Technology Services on the Open Web(Discussion Paper No. 2019-030; TILEC). Tilburg University. https://papers.ssrn.com/sol3/paper s.cfm?abstract_id $=3391913$

Grece, C. (2017). The EU online advertising market - Update 2016 [Report]. European Audiovisual Observatory. https://rm.coe.int/the-eu-online-advertising-market-update-2017/168078f2b3

Harvey, W. S. (2011). Strategies for conducting elite interviews. Qualitative Research, 11(4), 431-441. https://doi.org/10.1177/1468794111404329

I.A.B. Europe. (2014). Programmatic Trading [White Paper]. IAB Europe. https://iabeurope.eu/wp-cont ent/uploads/2020/03/IAB-Europe-Programmatic-Trading-White-Paper-July-2014.pdf

I.A.B. Europe. (2019). IAB Europe Report: AdEx Benchmark 2018 [Report]. IAB Europe. https://iabeurop e.eu/research-thought-leadership/iab-europe-report-adex-benchmark-2018/

Jacobides, M. G., Cennamo, C., \& Gawer, A. (2018). Towards a theory of ecosystems. Strategic Management Journal, 39(8), 2255-2276. https://doi.org/10.1002/smj.2904

James, L. (2019, October 22). Attorney General James Gives Update On Facebook Antitrust Investigation [Press release]. Letitia James NY Attorney General. https://ag.ny.gov/press-release/2019/attorney-ge neral-james-gives-update-facebook-antitrust-investigation

Just, N. (2018). Governing online platforms: Competition policy in times of platformization. Telecommunications Policy, 42(5), 386-394. https://doi.org/10.1016/j.telpol.2018.02.006

Kenney, M., Bearson, D., \& Zysman, J. (2019). The Platform Economy Matures: Pervasive Power, Private Regulation, and Dependent Entrepreneurs (2019-11 Working Paper; Berkeley Roundtable on the International Economy). University of California Berkeley. https://brie.berkeley.edu/sites/default/file s/platform_economy_matures_final.pdf

Kenyon, A. T. (2014). Assuming free speech. The Modern Law Review, 77(3), 379-408. https://doi.org/ 10.1111/1468-2230.12071

Kerber, W. (2019). Updating Competition Policy for the Digital Economy? An Analysis of Recent Reports in Germany, UK, EU, and Australia.

Lerner, A. V. (2014). The role of 'big data' in online platform competition. https://doi.org/10.2139/ssr $\underline{\text { n. } 2482780}$

Livingstone, S., \& Lunt, P. (2007). Representing Citizens and Consumers in Media and Communications Regulation. The ANNALS of the American Academy of Political and Social Science, 611(1), 51-65. https://doi.org/10.1177/0002716206298710

Lukes, S. (2005). Power: A radical view (2nd ed.). Palgrave Macmillan.

Lunt, P., \& Livingstone, S. (2011). Media regulation: Governance and the interests of citizens and consumers. SAGE Publications. 
Lynskey, O. (2017). Regulating 'Platform Power' (Working Paper No. 1/2017; LSE Law, Society and Economy). http://eprints.lse.ac.uk/id/eprint/73404

Moore, M. (2018). Democracy Hacked: Political Turmoil and Information Warfare in the Digital Age. Oneworld.

Moore, M., \& Tambini, D. (Eds.). (2018). Digital Dominance: The Power of Google, Amazon, Facebook and Apple. Oxford University Press.

Napoli, P. M. (2019). User Data as Public Resource: Implications for Social Media Regulation [Working Paper]. DeWitt Wallace Center for Media \& Democracy; Duke, Sanford School of Public Policy. http s://doi.org/10.2139/ssrn.3399017

Papacharissi, Z. (2010). A private sphere: Democracy in a digital age. Polity.

Paxton, K. (2019, September 9). Attorney General Paxton Leads 50 Attorneys General in Google Multistate Bipartisan Antitrust Investigation [Press release]. Attorney General of Texas. https://www.texasat torneygeneral.gov/news/releases/attorney-general-paxton-leads-50-attorneys-general-google-mult istate-bipartisan-antitrust

Petit, N. (2017). Significant Impediment to Industry Innovation: A Novel Theory of Harm in EU Merger Control? (White Paper No. 2017-1; ICLE Antitrust \& Consumer Protection Research Program).

Rochet, J., \& Tirole, J. (2006). Two-sided markets: A progress report. The RAND Journal of Economics, 37(3), 645-667. https://doi.org/10.1111/j.1756-2171.2006.tb00036.x

Rochet, J-C., \& Tirole, J. (2003). Platform Competition in Two-Sided Markets. Journal of the European Economic Association, 1(4), 990-1029. https://doi.org/10.1162/154247603322493212

Sabeel Rahman, K. (2018). Regulating Informational Infrastructure: Internet Platforms as the New Public Utilities. Georgetown Law Technology Review, 2(2), 234-251.

Schlosberg, J. (2018). Digital Agenda Setting: Reexamining the Role of Platform Monopolies. In Digital Dominance. The power of Google, Amazon, Facebook and Apple (pp. 202-218).

Schreieck, M., Wiesche, M., \& Krcmar, H. (2016). Design and Governance of Platform Ecosystems: Key concepts and issues for future research. ECIS 2016 Proceedings Research Papers, 76. http://aisel.a isnet.org/ecis2016_rp/76?utm_source=aisel.aisnet.org\%2Fecis2016_rp\%2F76\&utm_medium=PD F\&utm_campaign=PDFCoverPages

Schweitzer, H., Haucap, J., Kerber, W., \& Welker, R. (2018). Modernising the Law on Abuse of Market Power: Report for the Federal Ministry for Economic Affairs and Energy (Germany) [Report]. https://doi.o $\mathrm{rg} / 10.2139 / \mathrm{ssrn} .3250742$

Select Committee on Communications. (2018). UK advertising in a digital age (Report No. 116; HL Paper). House of Lords. https://publications.parliament.uk/pa/ld201719/ldselect/ldcomuni/116/11 6.pdf

Speicher, T., Ali, M., Venkatadri, G., Ribeiro, F., Arvanitakis, G., Benevenuto, F., Gummadi, K., Loiseau, P., \& Mislove, A. (2018). Potential for discrimination in online targeted advertising. Proceedings of Machine Learning Research, 81. http://proceedings.mlr.press/v81/speicher18a.html

Stigler Center. (2019). Committee for the Study of Digital Platforms Market Structure and Antitrust Subcommittee: Final Report [Report]. University of Chicago Booth School of Business. https://researc h.chicagobooth.edu/-/media/research/stigler/pdfs/digital-platforms---committee-report---stigler-ce nter.pdf?la=en \&hash=2D23583FF8BCC560B7FEF7A81E1F95C1DDC5225E\&hash=2D23583FF8BCC 


\section{B7FEF7A81E1F95C1DDC5225E}

Street, J. (2010). Mass media, politics and democracy. Macmillan International Higher Education.

Thompson, J. B. (2013). Ideology and modern culture: Critical social theory in the era of mass communication. John Wiley \& Sons.

Tiwana, A. (2014). Platform ecosystems: Aligning architecture, governance, and strategy. Morgan Kaufmann.

United Brands Company and United Brands Continentaal BV v Commission of the European Communities, C-27/76 (Court of Justice of the European Communities 14 February 1978). http://curi a.europa.eu/juris/liste.jsf?language $=$ en $\&$ jur $=C, T, F \&$ num $=27 / 76 \& t d=A L L$

Van Audenhove, L., \& Donders, K. (2019). Talking to People III: Expert Interviews and Elite Interviews. In H. V. Bulck, M. Puppis, K. Donders, \& L. V. Audenhove (Eds.), The Palgrave Handbook of Methods for Media Policy Research(pp. 179-197). Palgrave Macmillan. https://doi.org/10.1007/97 8-3-030-16065-4_10

Wagner, B., Moore, M., \& Tambini, D. (2018). Free Expression?-Dominant Information Intermediaries as Arbiters of Internet Speech. In Digital Dominance. The power of Google, Amazon, Facebook and Apple (pp. 219-240). Oxford University Press.

Warren, E. (2019, March 8). It's time to break up Amazon, Google and Facebook [Blog post]. Medium. https://medium.com/@teamwarren/heres-how-we-can-break-up-big-tech-9ad9e0da324c

Wismer, S., \& Rasek, A. (2017). Market definition in multi-sided markets: Hearing on Re-Thinking the Use of Traditional Antitrust Enforcement Tools in Multi-Sided Markets (DAF/COMP/WD(2017)33/FINAL). Organisation for Economic Co-operation and Development. http://www.oecd.org/officialdocuments/ publicdisplaydocumentpdf/?cote=DAF/COMP/WD\%282017\%2933/FINAL\&docLanguage $=E n$

Wu, T. (2018). The Curse of Bigness: Antitrust in the New Gilded Age. Columbia Global Reports.

Zenger, H., \& Walker, M. (2012). Theories of harm in European competition law: A progress report. In J. Bourgeois \& D. Waelbroeck (Eds.), Ten years of effects-based approach in EU competition law (pp. 185-209). Bruylant.

Zenith Media. (2019). Advertising Expenditure Forecasts March 2019. Zenith Media. https://www.zenit hmedia.com/wp-content/uploads/2019/03/Adspend-forecasts-March-2019-executive-summary.pdf

in cooperation with

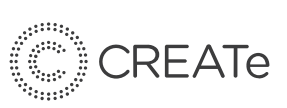

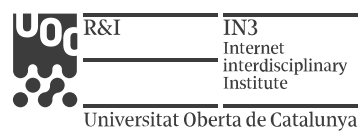

